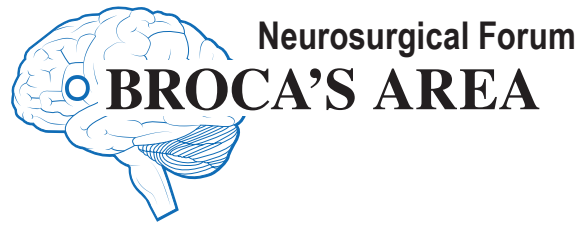

\section{Craniopharyngioma recurrence: the impact of tumor topography}

\author{
Ruth Prieto, MD, PhD, Inés Castro-Dufourny, MD, PhD, ${ }^{2}$ \\ Rodrigo Carrasco, MD, ${ }^{3}$ Laura Barrios, $\mathrm{BS},{ }^{4}$ and \\ José María Pascual, MD, PhD ${ }^{5}$
}

1'Department of Neurosurgery, Puerta de Hierro University Hospital, Madrid, Spain

2Department of Endocrinology, Hospital del Sureste, Madrid, Spain

32Department of Neurosurgery, Ramón y Cajal University Hospital, Madrid, Spain

${ }^{4}$ Statistics Department, Computing Technical Center, CSIC, Madrid, Spain

${ }^{5}$ Department of Neurosurgery, La Princesa University Hospital, Madrid, Spain

$\mathrm{W}$ E have read with great interest the article by Bao et al. ${ }^{1}$ (Bao Y, Pan J, Qi ST, et al: Origin of craniopharyngiomas: implications for growth pattern, clinical characteristics, and outcomes of tumor recurrence. J Neurosurg 125:24-32, July 2016). The authors retrospectively analyzed surgical outcomes in a series of 52 patients, consisting of 20 children and 32 adults, with recurrent craniopharyngiomas (CPs). Overall, radical removal was achieved in $85 \%$ of the cases, with a perioperative death rate of $3.85 \%$ and a satisfactory outcome in $48 \%$ of patients. Tumor recurrence represents one of the most challenging, unsettling issues regarding CPs owing to their unpredictability and the hazardous, demanding surgical treatment required. ${ }^{24}$ For this reason, we first congratulate $\mathrm{Bao}$ et al. for their excellent results $-\mathrm{a}$ high percentage of radical removal concurrent with remarkable low morbidity and mortality rates. Apart from their results, we wish to highlight the importance of their analysis, as they found that, among the potential factors that influence patient outcome following repeated surgery for CPs, tumor topography is a major variable that predicts both the postoperative status and the hypothalamic functional outcome. ${ }^{1}$ Comparison of recurrent CPs growing below (15 tumors) or above (37 tumors) the diaphragma sellae revealed that an acceptable outcome occurred in $87 \%$ of the infradiaphragmatic cases, whereas a good outcome was achieved in only $32 \%$ of the supradiaphragmatic tumors. In addition, the rates of postoperative obesity and cognitive impairment were higher in the supradiaphragmatic group, particularly in children. In this article we would like to emphasize the importance of a precise CP topography definition to accurately predict the individual surgical risks associated with the treatment of recurrent lesions.

Table 1 summarizes outcomes for the largest CP surgical series in which the results were compared between primary and recurrent cases., $, 5,7,8,10-13,15,27,29,32$ Although comparative evaluation among the cases in these series is complicated by their variable epidemiological composition and lack of validated parameters defining total removal, good outcome, and perioperative mortality, a uniform tendency toward a different outcome for primary and recurrent CPs can be recognized. The rate of radical excision falls dramatically for recurrent CPs, and operative mortality substantially increases for recurrent tumors. Even the most experienced and skilled neurosurgeons practicing aggressive removal in recurrent cases achieved gross-total resection in about only half of the lesions, with an associated mortality rate approximately 4 times higher than the observed incidence among first surgeries. ${ }^{32}$ The factors involved with such reduced surgical success in recurrent CPs have not been analyzed in detail. In most series, it is simply and vaguely stated that the worse outcome for recurrent CPs is largely attributed to the difficulties in tumor dissection posed by scarring from previous surgeries. ${ }^{12,15,29}$ Accordingly, the process of scarring induced by surgical maneuvers or dissection is believed to represent the explanation for the firm adherence usually found between recurrent CPs and contiguous neurovascular structures. ${ }^{27,28}$ Undoubtedly, adhesion strength and extent of tumor play fundamental roles in the possibility of achieving safe surgical removal of recurrent CPs, yet the underlying factors for the heterogeneous types of attachment among CPs have not been properly tackled. Regrettably, a comprehensive, irrefutable analysis of the pathological 
TABLE 1. Craniopharyngioma surgical series comparing the degree of removal and outcome between primary and recurrent cases

\begin{tabular}{|c|c|c|c|c|c|c|c|c|}
\hline \multirow[b]{2}{*}{ Authors \& Year } & \multicolumn{4}{|c|}{ Primary CPs } & \multicolumn{4}{|c|}{ Recurrent CPs } \\
\hline & No. & $\begin{array}{c}\% \text { Complete } \\
\text { Removal }\end{array}$ & $\begin{array}{l}\% \text { Good } \\
\text { Outcome }\end{array}$ & $\begin{array}{c}\% \text { Operative } \\
\text { Mortality }\end{array}$ & No. & $\begin{array}{c}\% \text { Complete } \\
\text { Removal }\end{array}$ & $\begin{array}{l}\% \text { Good } \\
\text { Outcome }\end{array}$ & $\begin{array}{c}\% \text { Operative } \\
\text { Mortality }\end{array}$ \\
\hline Yaşargil et al., 1990 & 112 & 90 & 76.8 & 9.8 & 32 & 56 & 34 & 40.6 \\
\hline Hoffman et al., 1992 & 50 & 90 & 56 & 2 & 17 & 30 & - & 12 \\
\hline Fahlbusch et al., 1999 & 148 & 45.7 (TC), 85.7 (TS) & 81 & 1.1 (TC), 0 (TS) & 20 & $21.1(\mathrm{TC}), 53.4$ (TS) & 58 & 10.5 (TC), 0 (TS) \\
\hline Van Effenterre \& Boch, 2002 & 122 & 59 & 85 & 2.5 & 29 & 25 & 83 & 10.3 \\
\hline Minamida et al., 2005 & 37 & 70.3 & - & 0 & 11 & 53 & - & 0 \\
\hline Karavitaki et al., 2005 & 121 & 18 & 52 & 1.8 & 43 & 0 & - & 24 \\
\hline Caldarelli et al., 2005 & 52 & 77 & - & 3.8 & 9 & 55.5 & - & 11.1 \\
\hline Gupta et al., 2006 & 234 & 8.1 & - & 7.4 & 26 & 3.8 & - & - \\
\hline Elliott et al., 2010 & 57 & 100 & 81 & 3.5 & 29 & 62 & 72 & 3.4 \\
\hline Koutourousiou et al., 2013 & 47 & 40.4 & - & 0 & 17 & 29.4 & - & 0 \\
\hline Šteňo et al., 2014 & 106 & 68.8 & - & 4 & 28 & 56.7 & - & 0 \\
\hline Cavallo et al., 2014 & 74 & 71.6 & - & - & 29 & 62.1 & - & - \\
\hline
\end{tabular}

$\mathrm{TC}=$ transcranial approach; $\mathrm{TS}=$ transsphenoidal approach; $-=$ not available.

characteristics accounting for the presumed disparity in adherence between primary and recurrent CPs is missing in the medical literature. Therefore, the majority of papers are limited to proposing breakage of the original leptomeningeal plane and/or loss of the peritumoral gliotic envelope as factors underlying the tighter attachments seen in recurrent CPs. . $^{28,30,32}$

The group headed by Juraj Šteňo has recently indicated that the nature of tumor adhesions observed among recurrent CPs varies depending on their topography. ${ }^{27}$ These authors found that CPs with an extraventricular location had fibrous adhesions incorporating small blood vessels between the tumor and the vascular structures of the suprasellar cistern, which were more problematic to detach than the gliotic scar between the tumor and the neural structures of the third ventricle. ${ }^{27}$ Bao et al. observed more extensive adhesions as well as a worse outcome among recurrent CPs not covered by the diaphragma sellae and in close relation with the third ventricle. ${ }^{1}$ Consequently, although the resectability of recurrent CPs rests on the surgeon's subjective judgment of the feasibility of removing tenacious adherences between tumor and neighboring structures, it is the objective damage inflicted on vital brain structures that will eventually determine the surgical outcome. Patient outcome following surgery for recurrent CPs has been found to depend mainly on the hypothalamic injury caused by surgical manipulation, ${ }^{1,8,12}$ as was evidenced by early attempts at removing primary CPs. ${ }^{20}$ In the particular case of recurrent CPs involving the third ventricle, the worst surgical outcome has been related to the loss of the gliotic envelope associated with previous surgical maneuvers. ${ }^{8,15,28,30}$ However, this general assertion should be questioned given the compelling histological evidence available. For instance, a thorough investigation of tumor boundaries in necropsy specimens and the surgical series by Kubota et al. did not reveal significant differences in the thickness of reactive gliosis around the tumor between primary and recurrent CPs. ${ }^{14}$ Moreover, we meticulously analyzed histological sections taken from an infundibulo-tuberal CP twice subjected to radical removal and found no significant differences regarding the thickness of the peritumoral gliotic layer between the first and subsequent biopsies. ${ }^{24}$ The only noticeable difference was a more extensively developed network of capillary vessels within the peritumoral gliosis in the sample taken from recurrent tumor (Fig. 1). Additional systematic analyses of tumor boundaries in large series of recurrent CPs are necessary to better understand the reasons for the apparently
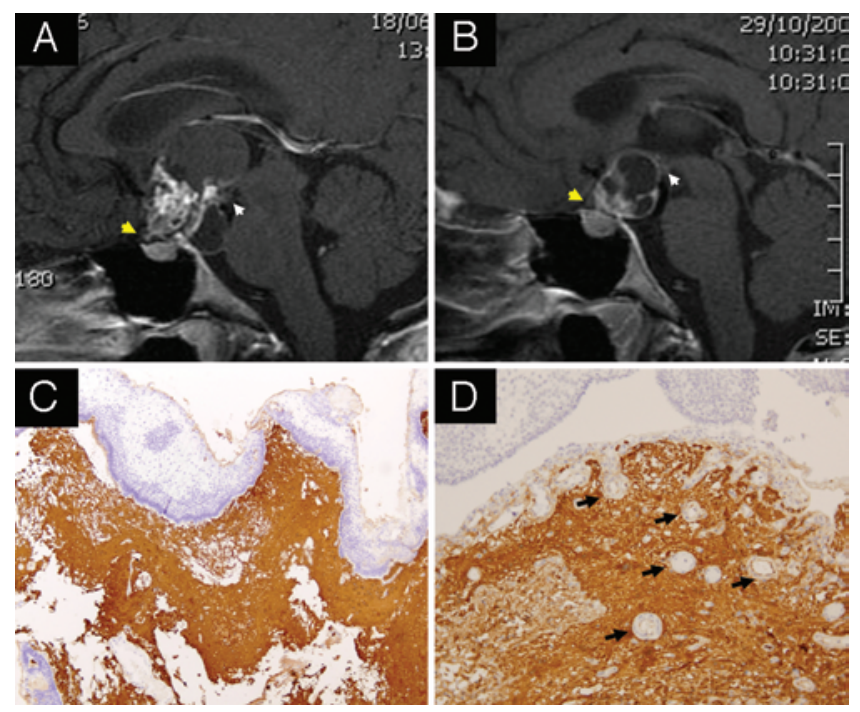

FIG. 1. Primary and recurrent infundibulo-tuberal, or not strictly intraventricular, CPs. Midsagittal contrast-enhanced T1-weighted MR images of a primary $\mathrm{CP}(\mathbf{A})$ and its recurrence $(\mathbf{B})$. In both cases the tumor causes forward, compressed distortion of the chiasm (yellow arrow) and downward displacement of the mammillary body (white arrow). Immunostaining for glial fibrillary acidic protein (GFAP) for primary (C) and recurrent (D) tumor specimens. Note that gliosis layer thickness (stained in brown) is similar in both specimens, but the network of capillary vessels (black arrows) within the layer of gliosis is much developed in the recurrent tumor. Figure is available in color online only. 
tighter attachment of these CPs to surrounding neurovascular structures.

The close contact observed between infundibulo-tuberal CPs and the hypothalamus in tumor specimens at autopsy accounts for the high risk of hypothalamic injury associated with attempts to excise recurrent lesions showing the same topography. ${ }^{14,26}$ This evidence supports the utility of thorough preoperative knowledge regarding the type of CP-hypothalamus relationship existing for each tumor, with the goal of choosing the surgical route with the best access to and view of the expected areas of tumor attachment. Thus, we suggest that the topographical separation of recurrent CPs into the 2 groups formulated by Bao et al., with the categories of "above" or "below" the diaphragma sellae, ${ }^{1}$ is too imprecise for a complete analysis of surgical risks. Grouping together all CPs growing above the diaphragma sellae fails to discern a fundamental difference, as regards the degree of hypothalamus involvement, between the tumors originating at the level of the pituitary stalk or those primarily developing within the third ventricle floor (TVF; Fig. 2). According to our systematic review of pathological, surgical, and MRI evidence for an accurate definition of $\mathrm{CP}$-third ventricle relationships, CPs originating in the upper neurohypophysis (median eminence) and adjacent basal hypothalamus (tuber cinereum) correspond to the infundibulo-tuberal, or not strictly intraventricular, category-a group of lesions embedded within the hypothalamus itself. ${ }^{16-19}$ In contrast, CPs originating in the pars tuberalis of the pituitary stalk, below an anatomically intact TVF, quite often push against the third ventricle, mimicking an intraventricular location. Hence, we included these seemingly intraventricular lesions in the suprasellar-pseudointraventricular category. ${ }^{16-19}$ From a surgical perspective, a precise distinction between both topographical categories is paramount.

Infundibulo-tuberal, or not strictly intraventricular, CPs

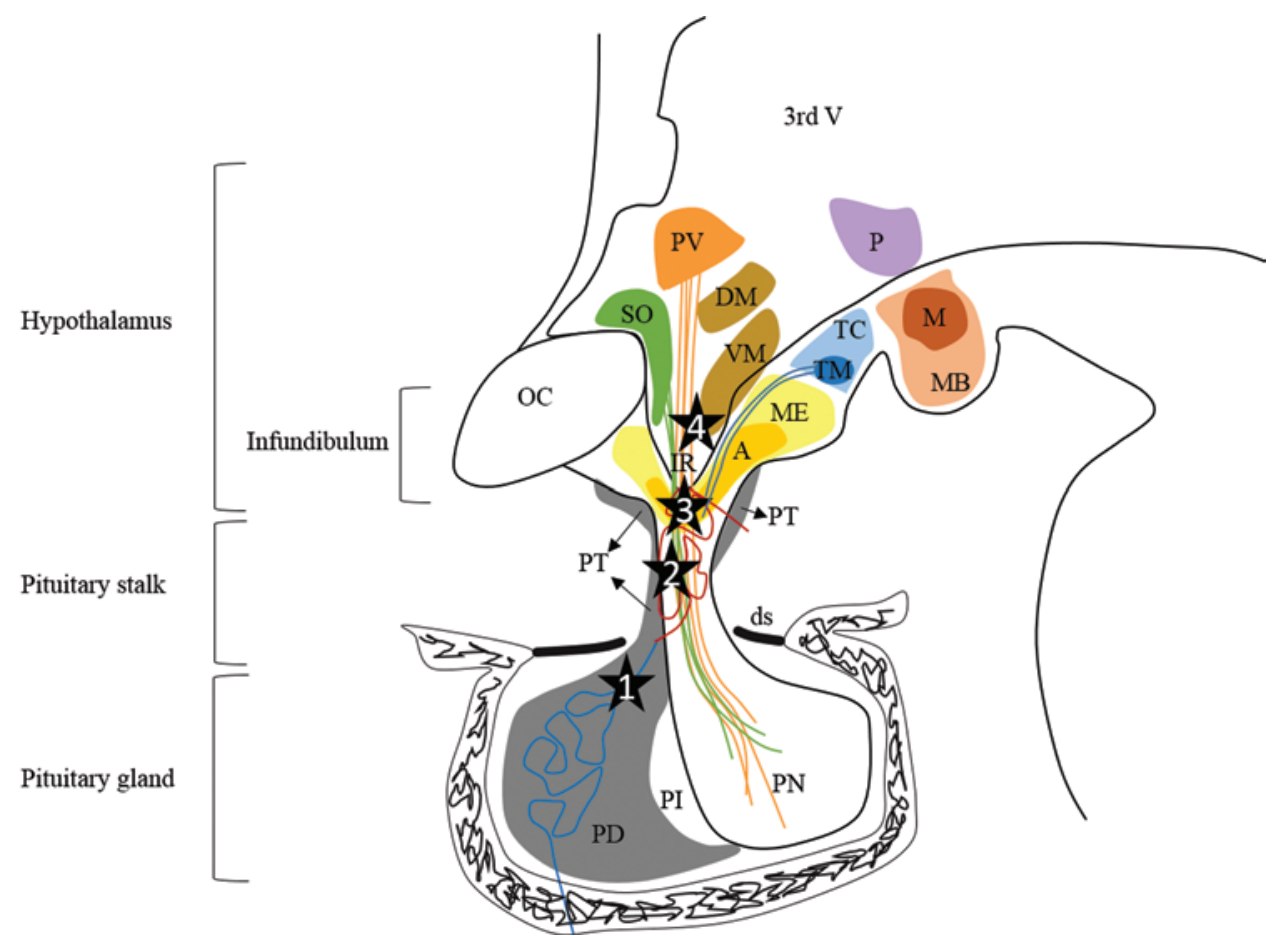

FIG. 2. Midsagittal hypothalamic-hypophyseal complex. Three major components of the hypothalamic-hypophyseal complex are the pituitary gland, the pituitary stalk, and the hypothalamus. The hypothalamus is part of the diencephalon, organized in a number of nuclei that have different morphological and functional features. The lower part of the hypothalamus surrounding the infundibular recess corresponds to the infundibulum. Black stars indicate the theoretical points where CPs may originate along this vertical axis to give rise to the 4 major CP topographies: 1 ) at the dorsal surface of the pituitary gland: sellar CPs $(<10 \%)$; 2$)$ from the pars tuberalis (PT) surrounding the infundibular stem: suprasellar-pseudointraventricular CPs (40\%); 3 ) at a subpial position within the neural layer of the median eminence (ME) and tuber cinereum (TC) of the TVF: infundibulo-tuberal or not strictly intraventricular CPs (40\%); and 4) beneath the ependymal layer of the infundibulum: strictly intraventricular CPs (10\%). Note that $80 \%$ of CPs originate either at the pituitary stalk or at the infundibulum. The supraoptic- and paraventricular-hypophyseal tracts are 2 bundles of unmyelinated fibers originating from magnocellular neurons of the supraoptic and paraventricular nuclei of the hypothalamus, which extend through the anterolateral infundibular walls and pituitary stem to the posterior lobe or pars nervosa of the pituitary gland. The tubero-hypophyseal tract (light blue) is a parvocellular system that projects from neurons of the tuber cinereum and terminates in the median eminence of the infundibulum, where the neurosecretory substances are released into the capillary loops of the hypophyseal portal system through which the hormonal release of the adenohypophysis or pars distalis of the pituitary gland is regulated. $A=$ arcuate nucleus; $\mathrm{DM}=$ dorsomedial nucleus of the hypothalamus; $\mathrm{ds}=$ diaphragma sellae; $\mathrm{IR}=$ infundibular recess; $\mathrm{M}=$ medial mammillary nucleus; $\mathrm{MB}=$ mammillary body; $\mathrm{OC}=$ optic chiasm; $\mathrm{P}=$ posterior nucleus; $\mathrm{PD}=$ pars distalis of the pituitary gland (adenohypophysis); $\mathrm{PI}=$ pars intermediate of the pituitary gland; $\mathrm{PN}=$ pars nervosa of the pituitary gland (posterior lobe); $\mathrm{PV}=$ paraventricular nucleus; $\mathrm{SO}=$ supraoptic nucleus; TM = tuberomammillary nucleus; VM = ventromedial nucleus; $3 r d \mathrm{~V}=$ third ventricle. Figure is available in color online only. 
should be considered true hypothalamic tumors because they usually replace the TVF while expanding into the third ventricle cavity. As infundibulo-tuberal CPs grow, they encroach upon the infundibulum and tuber cinereum, causing these structures to atrophy and transform into a thick layer of reactive gliosis firmly adhered to the wide center band of the tumor surface. ${ }^{18,26}$ This gliotic layer does not constitute a sealing barrier interposed between the tumor capsule and the hypothalamic nuclei; there are numerous histological reports of CPs showing peripheral, finger-like tumor protrusions through the gliosis, penetrating well into the vital nervous tissue of the hypothalamus. ${ }^{11,14,30}$ Consequently, the topographical category of infundibulo-tuberal CPs, representing almost $40 \%$ of such lesions in adults, is associated with the highest risk of hypothalamic injury, as well as the highest probability of recurrence, owing to small "islands" of tumor epithelium left behind, beyond the enveloping of reactive glia, even after radical surgical removal. ${ }^{18,24}$

Suprasellar-pseudointraventricular CPs lie within the arachnoid spaces of the suprasellar compartment. These lesions usually respect this leptomeningeal covering, which is interposed between the CP capsule and the TVF and can be used as a safe cleavage plane for separating tumor from the hypothalamus, even through blind extraction maneuvers. Nevertheless, in previous suprasellar-pseudointraventricular tumor operations, the thin arachnoid film between the tumor and the pia mater over the tuber cinereum may have been torn off, leading to the development of tight adherences at the dome of recurrent tumors, which may add to the risk of hypothalamic injury in subsequent surgeries. ${ }^{2,27}$

Finally, an additional topographical category of CPs involving the hypothalamus must be considered: the group of tumors originating either within the sella turcica below the diaphragma sellae or in the suprasellar compartment above the diaphragma sellae, which initially displace the TVF upward but eventually break into the hypothalamus and invade the third ventricle. This category of CPs, known in our classification scheme as secondary intraventricular CPs, may occupy 3 compartments at the time of diagnosis - the sellar area, suprasellar region, and third ventricle-presenting potentially tight adherences to each of them. Nevertheless, among this latter type, it is the destruction and gliotic transformation of the basal hypothalamus that markedly reduces the likelihood of safe radical removal of the mass. ${ }^{17,19}$

Modern high-resolution MRI sequences, such as heavily T2-weighted and fast imaging employing steady-state acquisition (FIESTA), may provide accurate information to define the relation between CPs and surrounding anatomical structures. In particular, these sequences have proven extremely useful in identifying the anatomical integrity and position of the TVF, even when it has been distorted by a large mass. ${ }^{9,25,31}$ Recently, we have verified that the type of anatomical distortion of the mammillary bodies caused by CPs constitutes reliable anatomical information to preoperatively differentiate lesions developing primarily within the TVF from suprasellar tumors, which are merely pushing the third ventricle upward. ${ }^{19}$ Precise recognition of the position and relative displacement of the mammillary bodies can be made on conventional T1weighted MRI, with an acute mammillary body angle (< $60^{\circ}$ ) characteristic of an infundibulo-tuberal topography, whereas an obtuse angle $\left(>90^{\circ}\right)$ denotes a primarily suprasellar CP pushing the intact TVF upward (pseudointraventricular type). ${ }^{9,19}$ Preoperative MRI identification of the type of optic chiasm distortion caused by the CP also allows precise definition of the tumor topography in many cases. Whereas infundibulo-tuberal CPs push the chiasm forward, those CPs that originally developed in the sellar and/or suprasellar compartments, beneath the chiasm, cause this structure to become displaced upward and subject to stretching deformation, usually associated with severe visual impairment and rapid optic atrophy. ${ }^{23}$ The mammillary body angle and the type of distortion of the optic chiasm can also be used to distinguish, among recurrent CPs, the infundibulo-tuberal from the suprasellarpseudointraventricular topographies (Fig. 3).

Apart from the valuable information provided by current neuroradiological studies, a thorough inquiry into the type and chronological presentation of clinical symptoms is essential to predict the anatomical relationship of the $\mathrm{CP}$, as well as the degree of functional involvement of the neural structures at surgical risk. In a historical cohort of CPs, a systematic survey of the correlation between groups of symptoms and degree of anatomical involvement of the hypothalamic-pituitary axis by the tumor allowed us to define 3 major syndromes: pituitary, infundibulo-tuberal, and hypothalamic. ${ }^{4}$ Each syndrome is respectively associated with structural damage of the hypophysis-pituitary stalk, the median eminence-tuber cinereum, and the third ventricle walls. The triad of Fröhlich's syndrome (obesity and sexual infantilism), drowsiness, and diabetes insipidus defines the infundibulo-tuberal syndrome, typical of CPs growing within the TVF or invading the median eminence and/or tuber cinereum (Fig. 2). A tight band of adherence around the tumor accounts for the high rate of incomplete

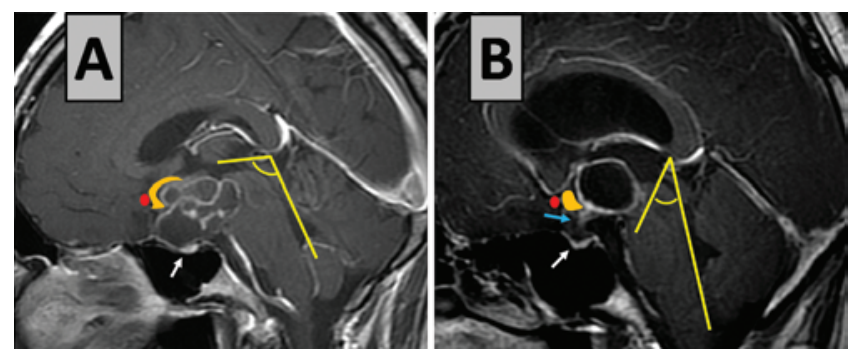

FIG. 3. Midsagittal contrast-enhanced MR images of recurrent CPs. A: Suprasellar-pseudointraventricular cystic multilobulated tumor occupying the suprasellar and interpeduncular cistern. Mammillary body angle (yellow) is obtuse, as this CP displaces the TVF upward. The pituitary stalk cannot be identified. The optic chiasm (orange) is stretched in front and over the tumor. The red dot anterior to the chiasm represents the location of the anterior communicating artery. B: Infundibulo-tuberal or not strictly intraventricular cystic tumor occupying the third ventricle cavity. The mammillary body angle (yellow) is acute because of downward displacement of the TVF by the tumor. The pituitary stalk (blue arrow) can be identified below the tumor, and the optic chiasm (orange) is compressed forward by the tumor. In both cases, the pituitary fossa is free of tumor and the pituitary gland can be identified (white arrow). Modified from Bao et al: $J$ Neurosurg 125:24-32, 2016. Published with permission. Figure is available in color online only. 
removals and recurrence associated with this subgroup of lesions. ${ }^{16-18,26}$ Furthermore, radical surgery of recurrent infundibulo-tuberal CPs is associated with the highest risk of irreversible injury to the hypothalamus and long-term disabling sequelae, such as progressive obesity, reduced intellectual performance, and anomalous behavior.

Finally, we would like to clarify the term "infundibulum," which has so often been used inaccurately in works related to CPs. In many textbooks, the word "infundibulum" is used to mean both the median eminence and the pituitary stalk. Nonetheless, from both a physiological and a surgical perspective, these 2 structures should be differentiated. "Infundibulum" is the classic Latin denomination to describe the hollow, funnel-shaped structure that connects the third ventricle to the pituitary gland. Such an anatomical link, however, is not made by direct contact between them, but rather through the pituitary stalk, a stem-like solid structure crossing the suprasellar cistern and the diaphragma sellae, also known as the "infundibular stem." While the infundibulum must be considered an integral part of the hypothalamus, whose walls delimit the boundaries of the infundibular recess of the third ventricle and contain the median eminence, its stem forms the posterior or neural lobe of the hypophysis (Fig. 2). The median eminence is the only hypothalamic region lacking a well-formed, functioning blood-brain barrier. The free access of blood-borne hormones and molecules to the median eminence makes this specialized hypothalamic region critical for body homeostasis regulation through different neuroendocrine systems. The adjacent paramedian area of gray neural tissue around the median eminence, enclosed by the optic tracts and the mammillary bodies, corresponds to the tuber cinereum, the basal portion of the hypothalamus visible on the brain undersurface.

The pituitary stalk contains the supraoptic- and paraventricular-hypophyseal tracts, the 2 long axonal pathways from the hypothalamus that convey and release vasopres$\sin$ and oxytocin to the posterior lobe of the hypophysis. The outer surface of the pituitary stalk is covered by a thin layer of hypophyseal glandular tissue, the pars tuberalis, which reaches the infundibulum to its upper junction with the optic chiasm. The embryonic primordium of the pars tuberalis is initially located at the lower part of Rathke's pouch, in close contact with the primitive stomodeum, although it eventually undergoes a forward and upward rotation toward the rudimentary median eminence, at the base of the diencephalon..$^{21,22}$ The morphology and extension of the pars tuberalis in adults varies from a narrow tongue covering only the anterior aspect of the pituitary stalk and median eminence to a pillowcase-like wrapping of the stalk and covering the entire ventral aspect of the median eminence and tuber cinereum. According to Erdheim's embryogenetic theory, CPs originate from epithelial cell nests, remnants of the craniopharyngeal duct, which are deposited preferentially at the upper and lower ends of the pars tuberalis. ${ }^{21}$ This theory could explain why $\mathrm{CP}$ topographies are concentrated around 2 categories, the suprasellar-pseudointraventricular and the infundibulotuberal (Fig. 2) ${ }^{21,22}$ Depending on the time the migration of epithelial remnants occurs in relation to the formation of the pia mater and arachnoid layers that cover the TVF,
CPs may develop at different depths across the thickness of the infundibular wall, from extracerebral intraarachnoid lesions expanding in the suprasellar area to subpial, truly intracerebral lesions developing within the neural tissue of the infundibulum and/or tuber cinereum. ${ }^{6}$ The high variability regarding the strength and extent of $\mathrm{CP}$ adherence to neighboring structures observed in the first surgical procedures must be related to the original topography of the lesion, and it will unquestionably influence the rate of ulterior recurrence. Craniopharyngioma remnants will be left behind during first surgeries, either deliberately or unknowingly, within the structures presenting the strongest adherence to tumor. These adhesions will happen predominantly within the basal hypothalamus for infundibulo-tuberal lesions and underneath the diaphragma sellae, at the dorsal aspect of the hypophyseal gland for sellar and/or suprasellar tumors. This concept of a close relation between the recurrence rate and the original topography of CPs is very much supported by the finding of coincidental locations for primary and recurrent CPs in the study by Bao et al. ${ }^{1}$

To conclude, contrary to the general belief that recurrent CP surgery is associated with higher morbidity and mortality rates given the difficulties posed by the scarring process induced during prior procedures, one should remember that the likelihood of a successful outcome following radical removal of a recurrence may largely depend on their original topography. The quality of life of patients with these lesions is mostly related to the preservation of hypothalamic functions. Consequently, instead of arguing for a common treatment philosophy for recurrent CPs, we believe that any surgical planning, including the choice of approach and the degree of tumor removal, should be custom-tailored for each recurrence, with the avoidance of hypothalamic injury as the major objective. Although recurrent CPs usually replicate the topography of the primary lesion, a thorough analysis of preoperative clinical and neuroradiological information is mandatory before planning the treatment strategy, including the assessment of T2-hyperweighted and FIESTA MRI sequences for lesions with ill-defined boundaries. Clinical assessment aims to differentiate the set of symptoms that defines the impairment of specific critical nodes along the hypothalamus-pituitary axis. Three major clinical conditions should be taken into consideration: pituitary, infundibulo-tuberal, and hypothalamic syndromes, which can be present in isolation or can overlap in some patients. With regard to MRI studies, evaluation of the mammillary body angle, as well as the pattern of distortion of the optic chiasm by the tumor, is fundamental to predict the exact relation between tumor and hypothalamus, along with the integrity of the TVF. Finally, the controversy regarding the influence that the peritumoral layer of gliosis has on the difficulty in dissecting CPs involving the hypothalamus is even greater for recurrent cases. Despite the widespread assumption that the higher risk of hypothalamic injury associated with the removal of recurrent CPs is related to loss of the gliotic layer resulting from previous surgeries, it may well be related to renewed gliosis activation around $\mathrm{CP}$ remnants, including the generation of a complex vascular network within the gliotic layer. Further studies are necessary to 
analyze boundaries of recurrent CPs to better understand the pathological basis underlying the degree of tumor adherence to surrounding brain tissue and, therefore, to define the possibilities of achieving safe radical removal of these challenging lesions.

\section{Acknowledgments}

We especially thank Crystal Smith, Reference Librarian of the Department of History of Medicine at the National Library of Medicine, National Institutes of Health, Bethesda, Maryland, and the staff at the Francis A. Countway Medical Library at Harvard Medical School, Boston, Massachusetts, for their invaluable help in obtaining some of the original research material used for this study. Finally, we express gratitude to George Hamilton for his critical review of the language and style of the manuscript.

\section{References}

1. Bao Y, Pan J, Qi ST, Lu YT, Peng JX: Origin of craniopharyngiomas: implications for growth pattern, clinical characteristics, and outcomes of tumor recurrence. J Neurosurg 125:24-32, 2016

2. Bosnjak R, Benedicic M, Vittori A: Early outcome in endoscopic extended endonasal approach for removal of supradiaphragmatic craniopharyngiomas: a case series and a comprehensive review. Radiol Oncol 47:266-279, 2013

3. Caldarelli M, Massimi L, Tamburrini G, Cappa M, Di Rocco C: Long-term results of the surgical treatment of craniopharyngioma: the experience at the Policlinico Gemelli, Catholic University, Rome. Childs Nerv Syst 21:747-757, 2005

4. Castro-Dufourny I, Carrasco R, Prieto R, Barrios L, Pascual JM: The infundibulo-tuberal syndrome caused by craniopharyngiomas: clinicopathological evidence from an historical French cohort (1705-1973). Pituitary 18:642-657, 2015

5. Cavallo LM, Frank G, Cappabianca P, Solari D, Mazzatenta D, Villa A, et al: The endoscopic endonasal approach for the management of craniopharyngiomas: a series of 103 patients. J Neurosurg 121:100-113, 2014

6. Ciric IS: Regional embryology, in Apuzzo MLJ (ed): Surgery of the Third Ventricle. Baltimore: Williams \& Wilkins, 1987, pp 167-174

7. Elliott RE, Hsieh K, Hochm T, Belitskaya-Levy I, Wisoff J, Wisoff JH: Efficacy and safety of radical resection of primary and recurrent craniopharyngiomas in 86 children. $\mathbf{J}$ Neurosurg Pediatr 5:30-48, 2010

8. Fahlbusch R, Honegger J, Paulus W, Huk W, Buchfelder M: Surgical treatment of craniopharyngiomas: experience with 168 patients. J Neurosurg 90:237-250, 1999

9. Gu Y, Zhang X: Mammillary body angle and craniopharyngioma. J Neurosurg 120:1241-1245, 2014

10. Gupta DK, Ojha BK, Sarkar C, Mahapatra AK, Mehta VS: Recurrence in craniopharyngiomas: analysis of clinical and histological features. J Clin Neurosci 13:438-442, 2006

11. Hoffman HJ, De Silva M, Humphreys RP, Drake JM, Smith ML, Blaser SI: Aggressive surgical management of craniopharyngiomas in children. J Neurosurg 76:47-52, 1992

12. Karavitaki N, Brufani C, Warner JT, Adams CB, Richards P, Ansorge $\mathrm{O}$, et al: Craniopharyngiomas in children and adults: systematic analysis of 121 cases with long-term follow-up. Clin Endocrinol (Oxf) 62:397-409, 2005

13. Koutourousiou M, Gardner PA, Fernández-Miranda JC, Tyler-Kabara EC, Wang EW, Snyderman CH: Endoscopic endonasal surgery for craniopharyngiomas: surgical outcome in 64 patients. J Neurosurg 119:1194-1207, 2013

14. Kubota T, Yamamoto S, Kohno H, Ito H, Hayashi M: [Operative procedures of craniopharyngioma estimated by autopsy findings (author's transl).] Neurol Med Chir (Tokyo) 20:341-354, 1980 (Jpn)
15. Minamida Y, Mikami T, Hashi K, Houkin K: Surgical management of the recurrence and regrowth of craniopharyngiomas. J Neurosurg 103:224-232, 2005

16. Pascual JM, Carrasco R, Prieto R, Gonzalez-Llanos F, Alvarez F, Roda JM: Craniopharyngioma classification. J Neurosurg 109:1180-1183, 2008 (Letter)

17. Pascual JM, González-Llanos F, Barrios L, Roda JM: Intraventricular craniopharyngiomas: topographical classification and surgical approach selection based on an extensive overview. Acta Neurochir (Wien) 146:785-802, 2004

18. Pascual JM, Prieto R, Carrasco R: Infundibulo-tuberal or not strictly intraventricular craniopharyngioma: evidence for a major topographical category. Acta Neurochir (Wien) 153:2403-2426, 2011

19. Pascual JM, Prieto R, Carrasco R, Barrios L: Displacement of mammillary bodies by craniopharyngiomas involving the third ventricle: surgical-MRI correlation and use in topographical diagnosis. J Neurosurg 119:381-405, 2013

20. Pascual JM, Prieto R, Castro-Dufourny I, Carrasco R, Strauss S, Barrios L: Development of intracranial approaches for craniopharyngiomas: an analysis of the first 160 historical procedures. Neurosurg Focus 36(4):E13, 2014

21. Pascual JM, Rosdolsky M, Prieto R, Strau $\beta$ S, Winter E, Ulrich W: Jakob Erdheim (1874-1937): father of hypophyseal-duct tumors (craniopharyngiomas). Virchows Arch 467:459-469, 2015

22. Prieto R, Pascual JM: Craniopharyngiomas with a mixed histological pattern: the missing link to the intriguing pathogenesis of adamantinomatous and squamous-papillary varieties? Neuropathology 33:682-686, 2013

23. Prieto R, Pascual JM, Barrios L: Optic chiasm distortions caused by craniopharyngiomas: clinical and magnetic resonance imaging correlation and influence on visual outcome. World Neurosurg 83:500-529, 2015

24. Prieto R, Pascual JM, Subhi-Issa I, Jorquera M, Yus M, Martínez R: Predictive factors for craniopharyngioma recurrence: a systematic review and illustrative case report of a rapid recurrence. World Neurosurg 79:733-749, 2013

25. Saeki N, Murai H, Kubota M, Fujimoto N, Iuchi T, Yamaura A, et al: Heavily T2 weighted MR images of anterior optic pathways in patients with sellar and parasellar tumours prediction of surgical anatomy. Acta Neurochir (Wien) 144:25-35, 2002

26. Šteňo J: Microsurgical topography of craniopharyngiomas. Acta Neurochir Suppl (Wien) 35:94-100, 1985

27. Šteňo J, Bízik I, Šteňo A, Matejčík V: Recurrent craniopharyngiomas in children and adults: long-term recurrence rate and management. Acta Neurochir (Wien) 156:113-122, 2014

28. Sweet WH: Recurrent craniopharyngiomas: therapeutic alternatives. Clin Neurosurg 27:206-229, 1980

29. Van Effenterre R, Boch AL: Craniopharyngioma in adults and children: a study of 122 surgical cases. J Neurosurg 97:3-11, 2002

30. Weiner HL, Wisoff JH, Rosenberg ME, Kupersmith MJ, Cohen H, Zagzag D, et al: Craniopharyngiomas: a clinicopathological analysis of factors predictive of recurrence and functional outcome. Neurosurgery 35:1001-1011, 1994

31. Xie T, Zhang XB, Yun H, Hu F, Yu Y, Gu Y: 3D-FIESTA MR images are useful in the evaluation of the endoscopic expanded endonasal approach for midline skull-base lesions. Acta Neurochir (Wien) 153:12-18, 2011

32. Yaşargil MG, Curcic M, Kis M, Siegenthaler G, Teddy PJ, Roth P: Total removal of craniopharyngiomas. Approaches and long-term results in 144 patients. J Neurosurg 73:3-11, 1990

\section{Disclosures}

The authors report no conflict of interest. 


\section{Response. Toward a better understanding of} craniopharyngioma

\section{Song-tao Qi, MD, PhD, and Yun Bao, MD, PhD}

Department of Neurosurgery, Nanfang Hospital, Southern Medical University, Guangzhou, Guangdong, People's Republic of China

We appreciate the comments made by Prieto et al. in response to our article. We have great interest in the mammillary body angle and the type of distortion of the optic chiasm used to distinguish among recurrent CPs. We agree that understanding the pathological basis underlying the degree of tumor adherence to surrounding brain tissue will lead to a better understanding of CPs and thus began to study their pathological basis 1 year ago. We thank Prieto et al. for their advice. 